\title{
Pengaruh Program PERMATA terhadap Wawasan Kebangsaan Mahasiswa di Universitas Negeri Padang
}

\author{
Tasya Juliani Jasmarnisa, Muhammad Prima Ersya \\ Program Studi Pendidikan Pancasila dan Kewarganegaraan \\ Universitas Negeri Padang \\ E-mail: tasyajuliani17@gmail.com
}

\section{ABSTRAK}

Penelitian ini bertujuan untuk menjelaskan dan mendeskripsikan peran program Permata dalam membentuk wawasan kebangsaan mahasiswa, nilai-nilai yang terdapat dalam program Permata, serta bentuk hambatan dan tantangan mahasiswa Universitas Negeri Padang dalam kegiatan Program Pertukaran Mahasiswa Tanah Air Nusantara (Permata) pada tahun 2018. Penelitian ini menggunakan metode kombinasi atau mix methods dengan menggunakan sequential exploratory (urutan penemuan) dengan teknik observasi, wawancara, kuesioner, dan dokumentasi. Hasil penelitian menunjukkan bahwa program permata memiliki pengaruh yang cukup signifikan dalam membentuk wawasan kebangsaan mahasiswa di Universitas Negeri Padang. Pertama, peran program Permata dalam meningkatkan wawasan kebangsaan yang dikelompokkan secara psikologis, sosial, universitas, dan negara dalam pengenalan kebudayan dan keberagaman yang ada di nusantara melaui metode belajar Jelajah Alam Sekitar (JAS) dan komunikasi antar budaya dengan mahasiswa Permata lain serta mahasiswa asli daerah. Kedua, penanaman nilai-nilai sosial yaitu nilai solidaritas, nilai toleransi, nilai keberagaman, nilai kebudayaan dan nilai persatuan dalam kehidupan berbangsa dan bernegara yang didapatkan ketikaprogram Permata dilaksanakan karena mahasiswa Permata asal Universitas Negeri Padang dikumpulkan dengan mahasiswa lain yang memiliki bahasa, ras, etnis, agama, dan kebiasaan yang beragam. Ketiga, terdapat beberapa hambatan dan tantangan yang harus dihadapi mahasiswa Permata ketika berada di lingkungan yang belum pernah ia datangi sebelumnya yaitu dari aspek bahasa, kebiasaan, cita rasa makanan, gaya bicara, serta cuaca dan iklim yang berbeda dengan sehingga mahasiswa Pemata asal Universitas Negeri Padang harus mampu untuk menyesuaikan diri dengan daerah universitas tujuan agar tidak menghalangi terbentuknya wawasan kebangsaan mahasiswa dan justru membangkitkan semangat dalam menerima keragaman dan kebudayaan yang ada di Indonesia.

Kata Kunci: permata, wawasan kebangsaan, pertukaran mahasiswa

\section{ABSTRACT}

This reseach is an aim to explain and descripted Permata program to form insight of the student nation, the value that in the Permata program, then form obstacles and student challenge of Universitas Negeri Padang in act of Pertukaran Mahasiswa Tanah Air Nusantara (Permata) at 2018. This research using a combination code or ix methods with 
using sequential exploratory (Invention arrange) with observation technic, interview, kuesioner, and documentation. The results of research showing that Permata program have enough influence in to form nation of student insight at the Universitas Negeri Padang. First, role of Permata program in raise up the nation insight that grouped in manner psychology, social, university, and country in introducing culturing and diversity that exist in nusantara through Jelajah Alam Sekitar (JAS) method and communication of each other culture with other Permata student and original student. Second, planting the social value is solidarity value, tolerance value, diversity value, dan unity value in nation life and stateless whos got when Permata program held cause Permata student from Universitas Negeri Padang has collected with other student who having other language, racis, ethnic, religion, and activity that diversity. Third, there is many obctacles and challenge that must be facing by the Permata student when they in the environtment that never they coming before is language aspect, activity, food taste, talk stye, and different weather until the Permata student from Universitas Negeri Padang should able to adaptation with pointing Univerity state so that not obstacling to form the insight of student nation dan so raising the spirit in accepting diversity dan culturing that exist in Indonesia.

Keywords : Permata, insight nation, student exchange

\section{PENDAHULUAN}

Pendidikan tinggi ialah salah satu pilar dalam pengembangan ilmu pengetahuan. Sesuai dengan tujuan pendidikan tinggi yang tertuang dalam Undang-Undang No. 12 Tahun 2012 tentang Pendidikan Tinggi Pasal 5, yaitu: berkembangnya potensi mahasiswa supaya menjadi manusia yang beriman dan bertakwa kepada Tuhan Yang Maha Esa serta berakhlak mulia, sehat, berilmu, cakap, kreatif, mandiri, terampil, kompeten, dan berbudaya untuk kepentingan bangsa. Dalam mewujudkan tujuan pendidikan tinggi untuk menciptakan manusia yang berbudaya, maka dirancanglah sebuah program Pertukaran Mahasiswa Tanah Air Nusantara (Permata) yang memiliki tujuan untuk meningkatkan wawasan kebangsaan mahasiswa.
Universitas Negeri Padang merupakan salah satu perguruan tinggi negeri yang ikut dalam program Permata. Universitas Negeri Padang telah mengikuti program Pertukaran Mahasiswa Tanah Air Nusantara selama 3 tahun (2016-2018). Pada tahun 2018, sebanyak 45 mahasiswa Universitas Negeri Padang yang diberangkatkan ke 11 Lembaga Perguruan Tinggi Keguruan (LPTK) untuk mengikuti program Pertukaran Mahasiswa Tanah Air Nusantara.

Semangat dan wawasan kebangsaan sangat penting untuk ditumbuh-kembangkan baik oleh pemerintah, instansi pendidikan maupun masyarakat karena rasa kebangsaan merupakan manifestasi dari rasa cinta terhadap negara, dan pada akhirnya akan membangkitkan kesadaran mengenai makna dan nilai dari rasa persatuan dan kesatuan 
bangsa (Siswono, 1996:17).

Berdasarkan Undang-undang Nomor 40 Tahun 2009 tentang Kepemudaan, Pasal 17 Ayat (2) memuat peran aktif pemuda sebagai kontrol sosial diwujudkan dengan memperkuat wawasan kebangsaan.

Latief (Kompas, 2011)

menyatakan saat ini wawasan

kebangsaan dinilai sudah menurun sehingga generasi muda seringkali mengalami krisis identitas, perkembangan wawasan kebangsaan generasi muda cukup memprihatinkan dan perlu mendapatkan perhatian serius. Hutabarat Delvira (Liputan6, 2018). Kota Padang mendapat peringkat ke-5 Indeks Kota Toleran (IKT) terendah dari 94 kota di Indonesia tahun 2018 versi Setara Institute. Hal ini tentunya juga berpengaruh terhadap sikap toleransi mahasiswa Universitas Negeri Padang.

Kurniawan (2009), mengemukakan bahwa wawasan kebangsaan merupakan cara pandang yang selalu utuh dan menyeluruh dalam lingkungan nusantara demi tercapainya tujuan nasional. Cara pandang yang dimaksud bagi bangsa Indonesia ialah wawasan kebangsaan yang mengacu pada kondisi pemanfaatan konstelasi geografi negara Indonesia, faktor kesejarahan, kondisi sosial-budaya, dan perkembangan lingkungan sehingga menumbuhkan rasa cinta pada tanah air. Maka dari itu, pemahaman mengenai wawasan kebangsaan memiliki aspek keanekaragaman yang memiliki pengertian bahwa negara Indonesia harus dapat menerima dan menghargai perbedaan suku, golongan, ras, warna kulit, asal-usul, keturunan, agama dan kepercayaan kepada Tuhan Yang Maha Esa, serta kedudukan sosial maupun status sosial.

Berdasarkan penelitian terdahulu mengenai program Permata dalam hal komunikasi antarbudaya oleh Inka Adrina Paramita (2016:95). Mahasiswa Permata dari Universias Sumatera Utara juga melakukan proses komunikasi antarbudaya ketika harus melakukan pertukaran ke Perguruan Tinggi Negeri lain yang ada di Indonesia. Interaksi yang dilakukan memiliki latar belakang kebudayaan yang berbeda. Hal ini menyebabkan mahasiswa Permata asal Universitas Sumatera Utara menjadi lebih paham mengenai budaya lain selain budayanya sendiri. Hasil penelitian di lapangan membuktikan bahwa seluruh mahasiswa. Ketika seseorang diharuskan untuk bertemu dengan seseorang yang memiliki latar belakang kebudayaan yang berbeda, pastilah Ia akan mengalami kecemasan atau ketidakpastian ketika akan berinteraksi.

Berdasarkan wawancara penulis dengan mahasiswa Permata asal Universitas Negeri Padang terdapat identifikasi masalah yang dirasakan mahasiswa Permata yaitu:

Mahasiswa Permata kesulitan berkomunikasi dengan mahasiswa lain karena tidak mengerti dengan bahasa daerah setempat;

Mahasiswa Permata kesulitan bergaul dengan mahasiswa asli daerah setempat karena pebedaan karakteristik budayanya; Perbedaan kebudayaan yang bertolak belakang mengakibatkan proses sosialisasi mahasiswa Permata berlangsung lama; (4) Adanya kesulitan sarana dan prasarana pendidikan yang dirasakan oleh 
mahasiswa Universitas Negeri Padang saat menjalani program Permata.

Berdasarkan permasalahan diatas, menurut informan dan analisis data kuantitatif yang telah dilakukaaan, mahasiswa Permata yang mengalami kesulitaan berkomunikasi dan bergaul dengan mahasiswa lain yang berbeda kebudayaan dengan dirinya secara berangsur-angsur dapat menerima dan memahami perbedaan karakteristik kebudayaan mahasiswa Permata lain serta kebudayaan daerah setempat. Proses sosialisasi mahasiswa Permata juga dipengaruhi oleh kepribadian dari mahasiswa Permata itu sendiri dalam bersosialisasi di lingkungan baru yang mempengaruhi kecepatan seseorang menjalin keakraban dengan mahasiswa lain. Sarana dan prasarana yang ada di universitas tujuan masih rendah menurut mahasiswa Permata.

Peniliti memberikan saran untuk keterbatasan solusi yang ada, yaitu diharapkan adanya pantauan khusus dari kementerian pendidikan dan kebudayaan terhadap mahasiswa yang megikuti program Permata dan universitas penerima yang menjalankan kegiatan-kegiatan dalam memperkenalkan kebudayaan setempat. Universitas tujuan juga diharapkan selalu melakukan peningkatan sarana dan prasarana proses pembelajaran agar setiap mahasiswa dapat belajar dengan nyaman dan aman. Namun dalam memberikan pengenalan budaya setempat universitas tujuan dinilai sudah baik.

Tujuan penulisan artikel ini adalah untuk menjelaskan dan mendeskripsikan peran program Permata dalam membentuk wawasan kebangsaan mahasiswa, nilai-nilai yang terdapat dalam program Permata, serta bentuk hambatan dan tantangan mahasiswa Universitas negeri Padang dalam kegiatan Permata. Apabila penelitian ini dilakukan harapan penuli adalah masyarakat mendapatkan informasi mengenai program Pertukaran Mahasiswa Tanah Air Nusantara (Permata) dalam meningkatkan wawasan kebangsaan mahasiswa dan pemerintah meningkatkan upayaupaya dalam mengembangkan wawasan kebangsaan mahasiswa sebagai perisai peradaban bangsa di tengah isu kemajemukan.

\section{METODE PENELITIAN}

Penelitian ini menggunakan metode penelitian kombinasi (mix methods). Metode penelitian kombinasi adalah metode penelitian yang menggabungkan antara metode kuantitatif dan metode kualitatif. Sugiyono (2017) menyatakan bahwa "kedua metode kualitatif dan kuantitatif dapat digabungkan tetapi digunakan secara bergantian". Penulis menggunakan sequential exploratory (urutan penemuan), yaitu metode penelitian kombinasi yang menggabungkan metode penelitian kulitatif dan kuantitatif secara berurutan, dimana pada tahap pertama penelitian ini dilakukan dengan metode penelitian kualitatif dan tahap kedua menggunakan metode kuantitatif. Lokasi penelitian ini adalah Universitas Negeri Padang, karena setelah mahasiswa Permata selesai menjalankan program maka kembali berkuliah di Universitas Negeri Padang. Informan yang digunakan sebanyak 11 orang dan sampel sebanyak 45 orang dari 45 populasi. Jenis data yang digunakan dalam penelitian ini adalah data 
primer dan data sekunder. Pengumpulan data dilakukan dengan wawancara terstruktur, kuesioner, observasi dan dokumentasi. Teknik analisis data kualitatif dilakukan dengan menggunakan model analisis interaksi untuk menganalisis data hasil penelitiannya tahapan pengumpulan data, reduksi data, penyajian data dan mengambil kesimpulan atau verifikasi data dan untuk kuantitatif menggunakan rumus persentase.

\section{HASIL DAN PEMBAHASAN}

Wawasan dapat berarti juga sebagai pandangan atau tujuan. Sedangkan kebangsaan adalah ciri-ciri atau identitas yang menandai asal bangsanya, atau golongan suatu bangsa (Badudu-Zain, 2001:122). Berdasarkan pengertian tersebut dapat dijelaskan bahwa wawasan kebangsaan adalah pandangan dilandasi kesadaran diri dari suatu warga negara akan diri dan lingkungannya dalam kehidupan berbangsa and bernegara. Peran program Permata membentuk wawasan kebangsaan mahasiswa yang dikelompokkan secara psikologis, sosial, universitas, dan negara yang saling berperan dalam menambah wawasan mahasiswa mengenai arti keberagaman dan kebudayaan yang ada di nusantara dengan mengumpulkan mahasiswa Permata yang berasal dari 11 LPTK ke satu tempat yang mana mahasiswanya memiliki perbedaan karakteristik, kebudayaan, agama, etnis, ras, agama dan bahasa.

Ridlo (2005:28) menyatakan bahwa pembelajaran yang mengeksplorasi lingkungan sekitar disebut jelajah alam sekitar atau JAS. Lebih lanjut dinyatakan bahwa alam sekitar ialah lingkungan di sekitar siswa, dapat berupa lingkungan alam, sosial, budaya, agama, dan sebagainya. Mahasiswa Permata diajak untuk mengenal kebudayaan setempat dengan mengunjungi tempat-tempat bersejarah atau wisata alam di daerah universitas tujuan sehingga mahasiswa Permata mengenal sejarah dan potensi Sumber Daya Alam yang ada di daerah tersebut.

Dalam kehidupan masyarakat nilai merupakan sesuatu untuk memberikan tanggapan atas perilaku, tingkah laku, dan segala sesuatu yang berkaitan dengan aktivitas masyarakat baik secara kelompok maupun individu (Puspandari, 2012). Fatimah dalam Nurfirdaus \& Risnawati (2019: 13) mengatakan bahwa dalam kehidupan di masyarakat terjadi proses saling mempengaruhi satu sama lain yang terus-menerus dan silih berganti dari proses tersebut timbul suatu pola kebudayaan dan pola tingkah laku yang sesuai dengan aturan, hukum, adat-istiadat, nilai dan norma sosial yang berlaku dalam masyarakat.

Berdasarkan temuan penulis, terdapat nilai-nilai yang terkandung dalam program Permata yang telah diurutkan dari nilai yang tertinggi hingga terendah yang dirasakan mahasiswa yaitu nilai solidaritas, toleransi, keberagaman, kebudayaan, dan persatuan. Berdasarkan temuan penulis terbentuk nilai-nilai sosial karena mahasiswa Permata berkumpul dalam satu tempat yaitu asrama yang telah disediakan dan memiliki kegiatan secara bersamasama serta saling berkomunikasi dan memperkenalkan kebudayaan masing-masing daerah sehingga mahasiswa asal Universitas Negeri 
Padang semakin kaya akan pengetahuan budaya atau Culture knowledge.

Berdasarkan kuesioner yang telah disebarkan pada 10 Juli 2019 adalah sebagai berikut.

Gambar 1. Histogram Persentase nilai yang Terdapat dalam Program Permata

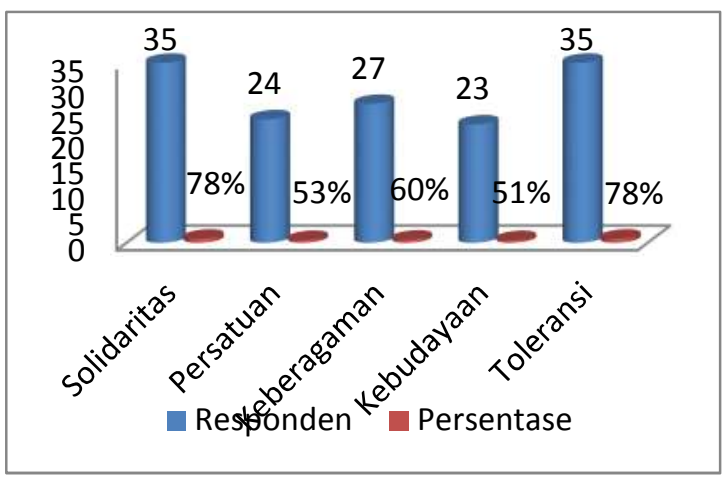

Sumber: Data Analisis Primer

Dari 45 responden mahasiswa Permata nilai solidaritas dirasakan oleh 35 responden dengan persentase $78 \%$, nilai persatuan dirasakan oleh 24 responden dengan persentase 53\%, nilai keanekaragaman dirasakan oleh 27 responden dengan persentase $60 \%$, nilai kebudayaan dirasakan oleh 23 responden dengan perrsentase $51 \%$, dan nilai toleransi dirasakan oleh 35 responden dengan persentase $78 \%$. Nilai toleransi dan nilai persatuan merupakan nilai yang sangat tingi dirasakan oleh maahsiswa Permata di universitas tujuan karena mahasiswa Permata asal Universitas Negeri Padang dikumpulkan dengan mahasiswa lain yang berasal dari agama, budaya, ras, dan latar belakang yang berbeda sehingga mahasiswa Perrmata belajar bertoleransi antar sesama mahasiswa dan merasa akrab dengan mahasiswa lain sehingga memunculkan rasa persatuan dan kesatuan.

Andrea L Rich dan Dennis M Ogawa dalam buku Larry A. Samovar dan Richard E. Porter Intercultural Commuication A Reader dalam Hajriadi (2017:16), komunikasi antarbudaya adalah komunikasi dengan orang-orang yang berbeda kebudayaan, misalnya antarsuku, bangsa, etnis, ras, dan antarkelas sosial. Nilai solidaritas merupakan nilai tertinggi karena keakraban antara mahasiswa Permata lain sangat tinggi dirasakan mahasiswa Permata asal Universitas Negeri Padang melalui kegiatan-kegiatan yang dilakukan secara bersama-sama ketika berada di universitas tujuan.

Menurut Kamus Besar Bahasa Indonesi (KBBI) kendala adalah halangan rintangan dengan keadaan yang membatasi, menghalangi atau mencegah pencapaian sasaran. Dalam hal ini kendala yang akan dikaji adalah kendala mahasiswa Permata dalam menyesuaikan diri di daerah universitas tujuan. Berdasaran temuan penulis, terdapat hambatan dan tantangan yang dihadapi mahasiswa Permata ketika berda di universitas tujuan yang diurutkan dari hambatan dan tantanagn yang terbesar hingga yang terkecil yaitu kebiasaan, bahasa, cita rasa makanan, gaya bicara serta cuaca dan iklim. Kebiasaan merupakan hambatan dan tantangan terbesar yang dirasakan mahasiswa Permata karena mahasiswa Permata yang bersal dari Kota Padang memiliki kebiasaan atau karakteristik budaya yang berbeda dengan daerah-daerah tempat mahasiswa Permata dikirimkan sehingga sempat mengalami gegar budaya atau culture shock.

Dikutip dari Hajriadi (2017), gejala gegar budaya yang dialami mahasiswa Permata yaitu : (a) gegar budaya sebagai nostalgia yaitu merasa 
rindu keluarga, teman, dan lingkungan yang familiar; (b) gegar budaya sebagai bentuk ketidakpuasan atas hambatan bahasa yaitu kurangnya komunikasi atau sulitnya berkomunikasi bisa menimbulkan frustasi dan perasaan terasing pada diri seseorang; (c) gegar budaya karena anggapan terhadap perbedaan nilainilai yaitu sulit menerima nilai-nilai baru. Awalnya mahasiswa Permata merasakan culture shock ketika berada di universitas tujuan namun lamakelamaan mahasiswa Permata mulai menyesuaikan diri dengan lingkungan daerah setempat.

\section{KESIMPULAN}

Berdasarkan temuan peneliti dan pembahasan dapat disimpulkan bahwa peran program Permata dalam meningkatkan wawasan kebangsaaan mahasiswa dikelompokkan secara psikologis, sosial, universitas, dan negara. Dalam mengembangkan wawasan kebangsaan diperlukan penanaman niai-nilai sosial yaitu solidaritas, persatuan, keberagamana, kebudayaan, dan toleransi bagi mahasiswa Permata dengan segala bentuk hambatan dan tantangan yang dihadapi mahasiswa sehingga pada akhirnya membentuk wawasan kebangsaan mahasiswa itu sendiri. Dengan berkumpulnya mahasiswa dari berbagai provinsi ke satu daerah dan hidup secara berdampingan dalam satu atap akan membawa pengaruh positif dalam kehidupan seseorang untuk dapat saling berinteraksi, serta menerima perbedaan, dan saling toleransi karena mahasiswa yang datang tersebut berasal dari berbagai daerah di Indonesia dengan membawa keanekaragaman budaya, ras, agama, suku, bahasa, dan kebiasaan sehingga mahasiswa belajar dan mengalami langsung untuk tidak membedakan dan menjalin tali silaturahmi dan membentuk ikatan kekerabatan dengan mahasiswa yang berasal dari 11 LPTK yang ada di Indonesia.

Penelitian ini akan memberikan kontribusi terhadap bidang ilmu sosial terutama pada mata kuliah pendidikan multikultural. Program Permata memberrikan pengetahuan dan pemahaman kepada mahasiswa yang mengikuti program tersebut mengenai keberagaman dan kebudayaan daerahdaerah yang ada di Indonesia yang memiliki perbedaan karakteristik dengan daerah lainnya karena negara Indonesia adalah negara yang multikultural.

\section{DAFTAR PUSTAKA}

Badudu, J. S, Sutan Mohammad Zain. (2001). Kamus Umum Bahasa Indonesia. Jakarta: Pustaka Sinar Harapan.

Hajriadi. (2017). Culture Shock Dalam Komunikasi Antar Budaya: Studi Deskriptif Kualitatif Pada Ikatan Pelajar Mahasiswa Musi Banyuasin Sumatera Selatan di Yogyakarta. Yogyakarta: Fakultas Ilmu Sosial dan Humaniora.

Hutabarat, Delvira. 2018. 94 Daftar Kota Toleransi Tertinggi dan Terendah Versi Setara Institute. Surat Kabar Online Liputan6. Diakses pada 9 Mei 2019.

Kurniawan, Fajar. (2009). Pendidikan Dasar Kewarganegaraan. Jakarta: Sri Gunting.

Latief. (2011). Krisis Identitas Generasi muda Kita. Edisi Kompas.com Kompas.com 08 Maret 2011 diakses pada 3 Mei 2019. 
Nurfirdaus, N., \& Risnawati, R. (2019). Studi Tentang Pembentukan Kebiasaan Dan Perilaku Sosial Siswa (Studi Kasus Di Sdn 1 Windujanten). Jurnal Lensa Pendas, 4(1), 36-46.

Paramita, Inka Adrina. (2016). Kompetensi Komunikasi Antarbudaya Mahasiswa Pertukaran Mahasiswa Tanah Air Nusantara (Permata). Medan: Universitas Sumatera Utara

Puspandari, Gita Eptika. (2012). NilaiNilai Pendidikan yang Terkandung Dalam Kesenian Menorek di Desa Gentawangi Kecamatan Jatilawang Kabupaten Banyumas. Yogyakarta: Universitas Negeri Yogyakarta.

Ridlo, S. (2005). Pendekatan Jelajah Alam Sekitar (JAS). Makalah. Dipresentasikan pada Semiar dan Lokakarya Pengembangan Kurikulum dan Desain Inovasi Pembelajaran Jurusan Biologi FMIPA UNNES dalam rangka pelaksanaan PHK A2. Semarang. Biologi FMIPA UNNES

Sugiyono. (2017). Metode Penelitian Kombinasi (Mixed Methods). Bandung: Alfabeta.

Undang-Undang Republik Indonesia Nomor 12 Tahun 2012 Tentang Pendidikan Tinggi.

Undang-Undang epublik Indonesia Nomor 40 Tahun 2009 Tentang Kepemudaan

Yudhohusodo, Siswono. (1996). Semangat Baru Nasionalisme Indonesia. Jakarta: Yayasan Pembangunan Bangsa 